\title{
Impact of Maintenance Therapy for Patients with Non-small Cell Lung Cancer in a Real-world Setting
}

\author{
KIYOTAKA YOH ${ }^{1}$, YASUSHI GOTO ${ }^{2}$, YOICHI NAITO ${ }^{3}$, KAZUMA KISHI $^{4}$, \\ KIYOSHI MORI ${ }^{5}$, KATSUYUKI HOTTA ${ }^{6}$, YUKIO HOSOMI ${ }^{7}$, KAZUHIKO YAMADA ${ }^{8}$, \\ CHIHARU TANAI ${ }^{9}$, YOSHIO TOMIZAWA ${ }^{10}$, AKIRA INOUE ${ }^{11}$, YOSHINORI HASEGAWA $^{12}$, \\ MAKOTO NISHIO ${ }^{13}$, YASUO OHASHI ${ }^{14}$ and HIDEO KUNITOH ${ }^{15}$ \\ Departments of ${ }^{1}$ Thoracic Oncology, and ${ }^{3}$ Breast and Medical Oncology, \\ National Cancer Center Hospital East, Kashiwa, Japan; \\ ${ }^{2}$ Department of Thoracic Oncology, National Cancer Center Hospital, Tokyo, Japan; \\ ${ }^{4}$ Department of Respiratory Medicine, Respiratory Center, Toranomon Hospital, Tokyo, Japan; \\ ${ }^{5}$ Department of Thoracic Disease, Tsuboi Cancer Center Hospital, Koriyama, Japan; \\ ${ }^{6}$ Department of Respiratory Medicine, Okayama University Hospital, Okayama, Japan; \\ ${ }^{7}$ Department of Thoracic Oncology and Respiratory Medicine, \\ Tokyo Metropolitan Cancer and Infectious Diseases Center Komagome Hospital, Tokyo, Japan; \\ ${ }^{8}$ Department of Internal Medicine, Kurume University School of Medicine, Kurume, Japan; \\ ${ }^{9}$ Division of Respirology, NTT Medical Center Tokyo, Tokyo, Japan; \\ ${ }^{10}$ Department of Respiratory Medicine, National Hospital Organization Nishigunma Hospital, Gunma, Japan; \\ ${ }^{11}$ Department of Palliative Medicine, Tohoku University School of Medicine, Sendai, Japan; \\ ${ }^{12}$ Department of Respiratory Medicine, Nagoya University Graduate School of Medicine, Nagoya, Japan; \\ ${ }^{13}$ Department of Thoracic Medical Oncology, \\ The Cancer Institute Hospital of Japanese Foundation for Cancer Research, Tokyo, Japan; \\ ${ }^{14}$ Department of Integrated Science and Engineering for Sustainable Society, Chuo University, Tokyo, Japan; \\ ${ }^{15}$ Department of Medical Oncology, Japanese Red Cross Medical Center, Tokyo, Japan
}

\begin{abstract}
Background: The purpose of this study was to explore the role of maintenance therapy for patients with advanced non-small cell lung cancer (NSCLC) in a realworld setting. Patients and Methods: This was a prospective observational cohort multicenter study. Eligible patients were observed from initiation of first-line platinum-based chemotherapy until final follow-up. Results: Between 2010 and 2011, a total of 864 patients were enrolled in this study. The primary study population was 396 patients who had progressive disease during observation after first-line chemotherapy without maintenance. Of these, 113 patients (29\%) did not receive second-line therapy. In contrast, only $18 \%$ of patients who had progressive disease during
\end{abstract}

Correspondence to: Kiyotaka Yoh, MD, Department of Thoracic Oncology, National Cancer Center Hospital East, 6-5-1 Kashiwanoha, Kashiwa, Chiba 277-8577, Japan. Tel: +81 471331111, Fax: +81 471314724, e-mail: kyoh@east.ncc.go.jp.

Key Words: Non-small cell lung cancer, platinum-based chemotherapy, maintenance therapy, second-line therapy. maintenance therapy missed second-line therapy. Overall survival of patients without maintenance who received second-line therapy was similar to that of those who received maintenance, but no second-line therapy. Conclusion: Maintenance therapy for patients with advanced NSCLC might be an appropriate strategy to maximize the chance of receiving more active therapy.

Non-small cell lung cancer (NSCLC) accounts for approximately $85 \%$ of all lung cancers. Patients with newly diagnosed NSCLC tend to have unresectable disease and are suitable for systemic chemotherapy with or without radiotherapy. Worldwide, the standard of care for patients with advanced NSCLC without driver mutations such as $E G F R$ or $A L K$ gene rearrangements is first-line combination chemotherapy (1).

Platinum-based doublet chemotherapy, in particular, significantly improves overall survival and quality of life for patients with advanced NSCLC (2). Second-line therapy is recommended for patients who have disease progression during or after first-line therapy. In patients with advanced NSCLC, second-line therapy in the form of single-agent 
docetaxel, pemetrexed, or erlotinib has been shown to improve quality of life and disease-related symptoms while conferring modest survival benefits (3-5). However, in clinical practice, not all patients receive second-line therapy at the time of disease progression after first-line chemotherapy (6-9).

Maintenance therapy after first-line platinum-based chemotherapy has emerged as a promising strategy for the management of patients with advanced NSCLC (10). The use of pemetrexed or erlotinib as maintenance therapy showed survival benefits in phase III randomized trials of patients with advanced NSCLC whose disease had not progressed after first-line platinum-based chemotherapy (1112). However, its impact on overall survival appears to be marginal or negligible compared to survival among patients who are able to receive second-line therapy initiated at disease progression $(14,15)$. Furthermore, maintenance therapy after completion of four to six cycles of first-line chemotherapy may deprive the patient of a 'drug holiday' period. Recently, the American Society of Clinical Oncology proposed a conceptual framework to assess the value of cancer treatment options (16). It suggests that, along with efficacy and toxicity, there are two other important factors to consider when assessing treatment options for advanced disease: palliation of symptoms and treatment-free intervals.

The purpose of this study was to explore the potential role of maintenance therapy in the treatment of patients with advanced NSCLC in a real-world setting, in contrast with appropriate second-line therapy in those treated without maintenance. We specifically investigated the proportion of patients with advanced NSCLC who received second-line therapy at disease progression during observation after firstline platinum-based chemotherapy without maintenance therapy. We also assessed the reasons and factors that hindered them from receiving second-line therapy.

\section{Patients and Methods}

Study design. The Comprehensive Support Project for Oncology Research (CSPOR)-LC01 study was a prospective observational cohort multicenter study in Japan. Patients with advanced or postoperative recurrent NSCLC who had started receiving first-line platinum-based combination chemotherapy were eligible to participate in this study. Those who had received platinum-based post-surgical adjuvant chemotherapy or those with active concomitant malignancy were excluded. Therapeutic management was at the discretion of the treating physicians. In clinical practice of Japan, the number of treatment cycles of the first-line platinumbased chemotherapy is usually four, and follow-up intervals during the observation period are commonly every 3 to 4 weeks.

This study was conducted according to the Declaration of Helsinki and approved by the institutional review boards of the respective institutions, as well as by the Ethics Committee at the Public Health Research Foundation (approval number, H0219). With regard to informed consent, the opt-out method (which provides opportunities to target patients for rejection through information disclosure via posting and publication) was employed, without mandating informed consent from individuals based on Japan's Ethical Guidelines for Epidemiological Research in 2008. However, each institution responded by following the instructions from their respective institutional review boards and obtained informed consent from individual patients when those boards judged it necessary.

Data collection. Baseline patient characteristics including age, sex, Eastern Cooperative Oncology Group (ECOG) performance status (PS), smoking status, comorbidities (diabetes mellitus, cardiac disease, and interstitial lung disease), body mass index, histology, clinical stage according to the Cancer Staging Manual for Lung Cancer, Seventh Edition (17), EGFR and $A L K$ mutations status, complete blood count, and blood chemistry were obtained at enrollment. Treatment data included regimen, duration, and response to first-line platinum-based chemotherapy, along with regimens of maintenance, second-line, and third-line therapies. Maintenance therapy was regarded as part of first-line chemotherapy, even in the case of switch maintenance, in which one or more chemotherapeutic agents not included in the first-line are used. Reasons for administering or omitting second-line or third-line therapy were recorded. Eligible patients were observed from initiation of firstline chemotherapy until death or final follow-up in April 2013 for at least 18 months. Data were collected every 6 months.

Statistical analysis. The primary endpoint of this study was the proportion of patients who received second-line therapy at disease progression among those who were treated without maintenance therapy after first-line platinum-based chemotherapy. The secondary endpoints were the proportion of patients who received maintenance therapy after first-line chemotherapy, the proportion of those who received second-line therapy after maintenance therapy, and the proportion of those who received third-line therapy. The target number of patients was initially set at approximately 750 .

The association between baseline characteristics and administration of second-line therapy was explored in univariate and multivariate analyses. All comparisons between proportions were performed by Fisher's exact test. Multivariate analyses were performed using the logistic regression. Overall survival (OS) was defined as the interval between the date of the beginning of firstline chemotherapy and the date of death or the last documented follow-up. Survival was estimated by the Kaplan-Meier analysis method, and compared by log-rank test. $p$-Values of less than 0.05 were considered statistically significant.

\section{Results}

Study population. A total of 864 eligible patients with advanced or postoperative recurrent NSCLC were enrolled in the study between April 2010 and September 2011 from 30 Institutions in Japan. Patient characteristics are listed in Table I. Their median age was 65 (range=24-86) years, $27 \%$ were women, and $92 \%$ had an ECOG PS 0 or 1 . The majority of patients had adenocarcinoma histology (70\%), and advanced disease (92\%) consisted of 719 stage IV and 73 stage IIIB tumors. Central nervous system metastases at enrollment were observed in 165 patients (19\%). EGFR mutation status was assessed in $601(70 \%)$ of all patients, 
Table I. Patient characteristics.

\begin{tabular}{lc}
\hline Characteristic & $\mathrm{N}(\%)$ \\
\hline All patients & 864 \\
Age, median (range), years & $65(24-86)$ \\
$\quad \geq 70$ Years & $250(29)$ \\
Gender & \\
$\quad$ Female/male & $237 / 627(27 / 7)$ \\
ECOG PS & \\
0/1/2/3-4/unknown & $343 / 448 / 65 / 7 / 1(40 / 52 / 7 / 1)$ \\
Histology & \\
Ad/Sq/NSCLC (NOS)/other & $602 / 174 / 72 / 16(70 / 20 / 8 / 2)$ \\
Stage & \\
$\quad$ Advanced/recurrent/unknown & $792 / 71 / 1(92 / 8)$ \\
Smoking history & $173 / 686 / 5(20 / 79 / 1)$ \\
$\quad$ Never/ever/unknown & $653(76)$ \\
Comorbidities & $95(11)$ \\
$\quad$ None & $84(10)$ \\
Diabetes mellitus & $49(6)$ \\
Cardiac disease & $22.1(13-39.6)$ \\
Interstitial lung disease & \\
BMI, median (range), kg/m ${ }^{2}$ & $88 / 513 / 263(10 / 60 / 30)$ \\
EGFR mutation status & $11 / 42 / 811(1 / 5 / 94)$ \\
$\quad$ Mutant/wild/unknown & \\
ALK rearrangement & \\
Positive/negative/unknown & \\
\hline
\end{tabular}

Ad: Adenocarcinoma; ECOG PS: Eastern Cooperative Oncology Group performance status; NOS: not otherwise specified; NSCLC: non-small cell lung cancer; Sq: squamous cell carcinoma; BMI: body mass index; EGFR: epidermal growth factor receptor; ALK: anaplastic lymphoma kinase.

and 88 patients had EGFR mutations (10\% of all patients). $A L K$ rearrangement was analyzed in only 53 patients $(6 \%)$ and was found in 11 patients only (1\% of all patients).

The details of the first-line platinum-based chemotherapy regimens are shown in Table II. Among all 864 patients, 331 patients (38\%) received cisplatin-based; 501 (58\%), carboplatin-based; and 33 (4\%), nedaplatin-based chemotherapy. The most frequently used regimens were cisplatin plus pemetrexed $(22 \%)$ in patients with nonsquamous NSCLC and carboplatin plus paclitaxel (30\%) those with squamous NSCLC. Combination of bevacizumab plus any platinum-based chemotherapy was administered to $24 \%$ of patients with non-squamous NSCLC.

The responses to first-line platinum-based chemotherapy were assessed in 818 patients, and were a complete response (CR) in four patients, a partial response (PR) in 292, stable disease (SD) in 313, and progressive disease in 168 patients; response was not evaluated in 41 patients. Thus, the overall response rate was $36 \%$. Of 609 patients who had CR, PR or SD after first-line platinum-based chemotherapy, 206 patients $(34 \%)$ received maintenance therapy. Maintenance therapy consisted of $76 \%$ for continuation maintenance and

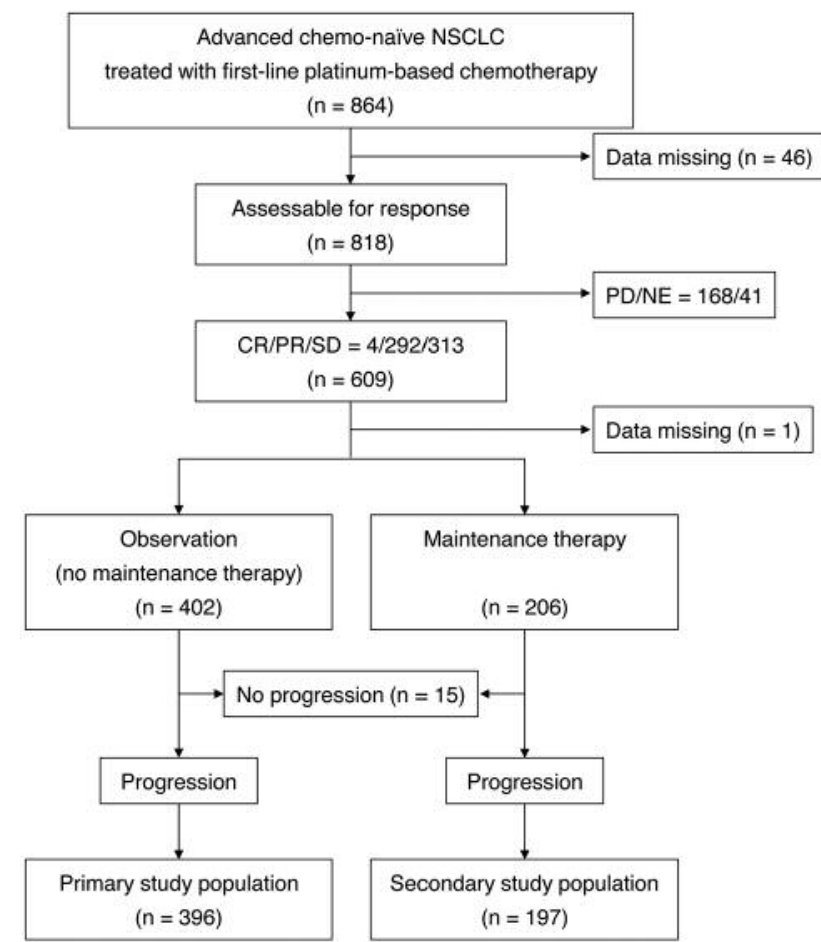

Figure 1. Study population for Comprehensive Support Project for Oncology Research-LC01. Administration of second-line therapy was assessed in primary and secondary study populations of patients with advanced non-small cell lung cancer (NSCLC). CR: Complete response; $N E$ : not evaluable; $P D$ : progressive disease; PR: partial response; $S D$ : stable disease.

$24 \%$ for switch maintenance. The regimens of maintenance therapy included bevacizumab in 69 patients, pemetrexed in 69 , bevacizumab plus pemetrexed in $27, \mathrm{~S}-1$ in 15 , erlotinib in four and other agents in 22 patients.

Administration of second-and third-line therapy. Among the 609 patients who had CR, PR or SD after first-line platinumbased chemotherapy, 402 were followed-up without maintenance therapy, of whom, 396 patients of them had disease progression during observation, and they were considered as the primary study population (Figure 1). Of these, 283 patients $(71 \%)$ received second-line therapy at disease progression and 113 patients $(29 \%)$ did not and received best supportive care alone. Among the 283 patients receiving second-line therapy, the most frequently administered second-line agents were docetaxel in 129 , pemetrexed in 55, and erlotinib in 27 (Table II). Reasons for not receiving second-line therapy at disease progression were decline of PS (62 patients), patient refusal (19 patients), death from any cause (eight patients), and other causes (24 patients). The most frequent reason for decline of PS was disease progression. The baseline patient characteristics did 
Table II. Summary of first-line and second-line therapies.

First-line platinum-based chemotherapy

\begin{tabular}{|c|c|c|c|}
\hline \multicolumn{2}{|c|}{ Non-squamous NSCLC $(\mathrm{N}=690)$} & \multicolumn{2}{|c|}{ Squamous NSCLC $(\mathrm{N}=174)$} \\
\hline Regimen & $\%$ & Regimen & $\%$ \\
\hline Cisplatin + pemetrexed & 22 & Carboplatin + paclitaxel & 30 \\
\hline Carboplatin + pemetrexed & 18 & Cisplatin + gemcitabine & 19 \\
\hline Carboplatin + paclitaxel & 17 & Carboplatin $+\mathrm{S}-1$ & 11 \\
\hline Carboplatin + paclitaxel + bevacizumab & 13 & Carboplatin + gemcitabine & 7 \\
\hline Cisplatin + docetaxel & 6 & Nedaplatin + docetaxel & 7 \\
\hline Carboplatin + pemetrexed + bevacizumab & 4 & Cisplatin + docetaxel & 5 \\
\hline Cisplatin + docetaxel + bevacizumab & 3 & Nedaplatin + irinotecan & 5 \\
\hline Cisplatin + gemcitabine & 3 & Cisplatin + vinorelbine & 4 \\
\hline Carboplatin + gemcitabine & 2 & Nedaplatin + paclitaxel & 4 \\
\hline Other & 12 & Other & 8 \\
\hline \multirow[t]{2}{*}{ Second-line therapy } & Without maintenance therapy $(\mathrm{N}=396)$ & \multicolumn{2}{|c|}{ With maintenance therapy $(\mathrm{N}=197)$} \\
\hline & $\mathrm{N}(\%)$ & \multicolumn{2}{|c|}{$\mathrm{N}(\%)$} \\
\hline Docetaxel & $129(32)$ & \multicolumn{2}{|c|}{$62(32)$} \\
\hline Pemetrexed & $55(14)$ & \multicolumn{2}{|c|}{$36(18)$} \\
\hline Erlotinib & $27(7)$ & \multicolumn{2}{|c|}{$26(13)$} \\
\hline S-1 & $16(4)$ & \multicolumn{2}{|c|}{$8(4)$} \\
\hline Gefitinib & $9(2)$ & \multicolumn{2}{|c|}{$14(7)$} \\
\hline Other & $47(12)$ & \multicolumn{2}{|c|}{$16(8)$} \\
\hline None (BSC) & $113(29)$ & \multicolumn{2}{|c|}{$35(18)$} \\
\hline
\end{tabular}

BSC: Best supportive care; NSCLC: non-small cell lung cancer.

not significantly differ between the group with decline of PS and the group of patient refusal. Of 197 patients who had disease progression during maintenance therapy, 162 patients (82\%) received second-line therapy and only 35 patients (18\%) did not. The most frequently administered drug was docetaxel (62 patients) (Table II). Decline of PS (51\%) was the principal reason for not receiving second-line therapy.

Third-line therapy was administered to 258 patients who had disease progression after second-line therapy. The most frequently administered agents were docetaxel (20\%), erlotinib (19\%), and pemetrexed (16\%).

\section{Association between clinical characteristics and administration} of second-line therapy. We performed univariate and multivariate analyses to identify the association between clinical characteristics and administration of second-line therapy. Results of univariate analysis are shown in Table III. In those who were followed-up without maintenance therapy, $31 \%$ of patients with an initial PS of 1-4 were unable to receive second-line therapy at disease progression, as compared with $22 \%$ of those with PS 0 [odds ratio $(\mathrm{OR})=1.79, p=0.01$ ]. Eighty-eight percent of $E G F R / A L K$-positive patients received second-line therapy compared to $70 \%$ of patients with
$E G F R / A L K$-negative/unknown status $(p=0.08)$. Only PS 1 or worse and the use of non-cisplatin were correlated with hindrance of administration of second-line therapy in univariate analysis. Response to first-line platinum-based chemotherapy (CR/PR versus SD) was not a factor associated with administration of second-line therapy. Based on the results of the univariate analysis, the multivariate analysis was performed using five variables: PS, EGFR/ALK status, smoking, comorbidities, and platinum agent (Table IV). The results of the multivariate analysis showed that PS was the only significant independent variable predicting administration or not of second-line therapy $(p=0.02)$.

Overall survival. Among the 864 eligible patients, survival analysis was assessed in 840 . The median follow-up time was 24.6 months (range=0.5-37.2 months). At the time of this analysis, 552 death events $(66 \%)$ had been recorded. The median OS for 840 patients was 16.2 months and the 1-year survival rate was $56 \%$ (95\% confidence interval $=52-59 \%$ ). The median OS for the 84 patients harboring EGFR mutation was 21.1 months and the 1-year survival rate was $86 \%(95 \%$ confidence interval $=77 \%$ to $92 \%$ ). The median OS of 205 assessable patients who had CR, PR or SD after first-line 
Table III. Univariate analysis of association between clinical characteristics and second-line therapy administration (observation without maintenance therapy).

\begin{tabular}{|c|c|c|c|c|}
\hline \multirow[b]{2}{*}{ Variable } & \multicolumn{2}{|c|}{$\begin{array}{l}\text { No. of patients treated } \\
\text { with second-line } \\
\text { therapy }(\%)\end{array}$} & \multirow[b]{2}{*}{$\begin{array}{c}\text { OR } \\
(95 \% \mathrm{CI})\end{array}$} & \multirow[b]{2}{*}{$p$-Valu } \\
\hline & Yes & No & & \\
\hline Total & $283(71)$ & $113(29)$ & & \\
\hline \multicolumn{5}{|l|}{ Age, years } \\
\hline$<70 / \geq 70$ & $\begin{array}{l}187(73) \\
96(66)\end{array}$ & $\begin{array}{l}68(27) \\
45(34)\end{array}$ & $\begin{array}{c}1.29 \\
(0.82-2.02)\end{array}$ & 0.29 \\
\hline \multicolumn{5}{|l|}{ Gender } \\
\hline Male/female & $\begin{array}{l}215(70) \\
68(75)\end{array}$ & $\begin{array}{l}90(30) \\
23(25)\end{array}$ & $\begin{array}{c}0.81 \\
(0.47-1.38)\end{array}$ & 0.50 \\
\hline \multicolumn{5}{|l|}{ PS } \\
\hline $0 / 1-4$ & $\begin{array}{l}129(78) \\
154(67)\end{array}$ & $\begin{array}{l}36(22) \\
77(33)\end{array}$ & $\begin{array}{c}1.79 \\
(1.13-2.84)\end{array}$ & 0.01 \\
\hline \multicolumn{5}{|l|}{ Histology } \\
\hline Ad/non-Ad & $\begin{array}{l}176(73) \\
107(69)\end{array}$ & $\begin{array}{l}65(27) \\
48(31)\end{array}$ & $\begin{array}{c}1.21 \\
(0.78-1.89)\end{array}$ & 0.42 \\
\hline \multicolumn{5}{|l|}{ CNS metastases } \\
\hline No/yes & $\begin{array}{l}234(72) \\
49(67)\end{array}$ & $\begin{array}{l}89(28) \\
24(33)\end{array}$ & $\begin{array}{c}1.29 \\
(0.75-2.22)\end{array}$ & 0.39 \\
\hline \multicolumn{5}{|l|}{$E G F R / A L K$ status } \\
\hline Positive/negative/unknown & $\begin{array}{l}28(88) \\
255(70)\end{array}$ & $\begin{array}{c}4(12) \\
109(30)\end{array}$ & $\begin{array}{c}2.30 \\
(0.77-6.82)\end{array}$ & 0.08 \\
\hline \multicolumn{5}{|l|}{ Smoking } \\
\hline Never/ever & $\begin{array}{c}57(79) \\
226(70)\end{array}$ & $\begin{array}{l}15(21) \\
98(30)\end{array}$ & $\begin{array}{c}1.65 \\
(0.89-3.05)\end{array}$ & 0.11 \\
\hline \multicolumn{5}{|l|}{ Comorbidities } \\
\hline No/yes & $\begin{array}{l}215(74) \\
68(65)\end{array}$ & $\begin{array}{l}77(26) \\
36(35)\end{array}$ & $\begin{array}{c}1.48 \\
(0.91-2.39)\end{array}$ & 0.12 \\
\hline \multicolumn{5}{|l|}{ Platinum agent } \\
\hline Cisplatin/non-cisplatin & $\begin{array}{l}121(79) \\
162(67)\end{array}$ & $\begin{array}{l}32(21) \\
81(33)\end{array}$ & $\begin{array}{c}1.89 \\
(1.18-3.03)\end{array}$ & 0.009 \\
\hline $\begin{array}{l}\text { First-line CT response } \\
\text { CR/PRSD }\end{array}$ & $\begin{array}{l}114(72) \\
169(71)\end{array}$ & $\begin{array}{l}45(28) \\
68(29)\end{array}$ & $\begin{array}{c}1.02 \\
(0.65-1.59)\end{array}$ & 1.00 \\
\hline
\end{tabular}

Ad: Adenocarcinoma; CI: confidence interval; CNS: central nervous system; CR: complete response; CT: chemotherapy; OR: odds ratio; PR: partial response; PS: performance status; SD: stable disease; EGFR: epidermal growth factor receptor; ALK: anaplastic lymphoma kinase.

chemotherapy and received maintenance therapy was significantly longer than that of the 400 assessable patients without who underwent observation maintenance therapy (21.4 versus 16.1 months, $p<0.0001)$.

Among the 394 assessable patients who had disease progression during observation after first-line chemotherapy without maintenance therapy, OS for patients receiving second-line therapy (283 patients) was 17.7 months as opposed to 11.0 months for those not receiving second-line therapy (111 patients). Of 196 assessable patients who had disease progression during maintenance therapy, OS for those receiving second-line therapy (161 patients) was 21.6 months as opposed to 13.1 months for those not (35 patients). Overall survival of patients without maintenance therapy who received second-line therapy was similar to that of those who received maintenance therapy but no second-line therapy (Figure 2).

\section{Discussion}

Our study, conducted in a real-world setting, is the largest multicenter cohort study to examine the impact of maintenance therapy on the administration of second-line therapy for patients with advanced NSCLC. We found that $29 \%$ of patients with advanced NSCLC who did not receive maintenance missed the opportunity of receiving appropriate second-line therapy at disease progression, despite clinical observation after first-line platinum-based chemotherapy. In contrast, only $18 \%$ of patients who did receive maintenance therapy missed the opportunity of receiving second-line therapy. Based on these results, administration of maintenance therapy after first-line chemotherapy does not appear to negatively affect the administration of second-line therapy. This may be due to the increased attention these patients receive in order to allow them participate in active therapy. In addition, we attempted to identify the factors that hinder patients from receiving second-line therapy, and found that only PS at baseline was a significant independent variable correlated with hindrance in receiving second-line therapy. There were no other significant variables, including response to first-line chemotherapy, predicting the administration of second-line therapy.

Maintenance therapy after first-line platinum-based chemotherapy is reported to be beneficial in the treatment of advanced NSCLC (11). Maintenance therapy consists of two principal methods: in continuation maintenance therapy, the regimen includes at least one of the agents given in first-line therapy, while in switch maintenance therapy, the regimen includes one or more agents that were not included in the first-line setting. Randomized phase III trials have shown significant improvements in progression-free survival and OS from both continuation (with pemetrexed) and switch (with pemetrexed or erlotinib) therapies $(12-13,18)$. However, several aspects of maintenance therapy are debated at every opportunity in the clinical setting, including the role of second-line therapy administration, treatment-free intervals, quality of life, and cost (11).

Fidias et al. reported the results of a phase III trial assessing switch maintenance therapy with docetaxel administered either immediately after first-line therapy or delayed at disease progression (14). Interestingly, the median OS for both of these groups was found to be identical. Our study also showed that survival of patients without maintenance who received second-line therapy was e similar to that of those who received maintenance therapy but no 
Table IV. Multivariate analysis of association between clinical characteristics and second-line therapy administration (observation without maintenance therapy).

\begin{tabular}{llcl}
\hline Variable & OR & $95 \%$ CI & $p$-Value \\
\hline PS: 0/1-4 & 1.77 & $1.09-2.86$ & 0.02 \\
EGFR/ALK status: negative/unknown, positive & 1.00 & $0.62-1.60$ & 0.98 \\
Smoking: never/ever & 1.53 & $0.79-2.97$ & 0.20 \\
Comorbidities: No/yes & 1.48 & $0.90-2.44$ & 0.12 \\
Platinum agent: cisplatin/non-cisplatin & 1.60 & $0.62-1.60$ & 0.06 \\
\hline
\end{tabular}

PS: Performance status; EGFR: epidermal growth factor receptor; ALK: anaplastic lymphoma kinase; OR: odds ratio; CI: confidence interval.

second-line therapy. Although our results were based on observational study, the impact on OS of maintenance therapy may be marginal compared to that when patients can receive second-line therapy timely at disease progression. In a phase III trial assessing pemetrexed as switch maintenance therapy, the crossover rate of post-protocol pemetrexed was only $18 \%$ for the placebo group (9). Therefore, post-progression treatment might have been suboptimal in the control arm, which could be one reason for the survival difference. The crucial issue then becomes why so many patients fail to receive appropriate second-line therapy in a timely fashion.

Our study has several limitations. Treatment decisions for each patient, including regimen selection, treatment cycles, the need for maintenance therapy and administration of secondline therapy, were made by their attending physician. Consequently, treatments varied widely from patient to patient, and any comparisons of survival according to maintenance and second-line therapy administration are biased. Another limitation is that the method of follow-up during observation after first-line platinum-based chemotherapy was uncontrolled, and surveillance was left at the discretion of the attending physician. Therefore, we were unable to assess potential associations between follow-up intervals during observation and the administration of second-line therapy. Furthermore, our study included only Japanese patients and therefore it might be difficult to address the generalizability of our results worldwide. However, there is no consensus on the optimal surveillance for this patient population, and we believe that this study reflects what is happening in the real world.

In conclusion, our findings indicate that approximately $30 \%$ of patients with advanced NSCLC missed an opportunity to receive appropriate second-line therapy at disease progression despite observation after first-line platinum-based chemotherapy. Multivariate analysis showed that PS at baseline was the only independent variable significantly correlated with hindrance of administration of second-line therapy. Our results suggest that maintenance therapy after first-line chemotherapy for advanced NSCLC might make patients more suitable for receiving more active therapy and thus contributes to longer survival. Given the

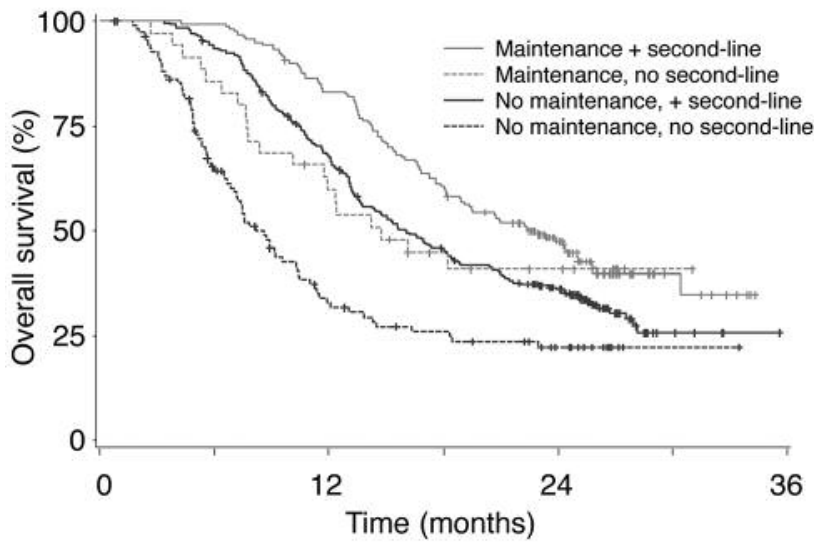

Figure 2. Overall survival from the beginning of first-line chemotherapy. Among the 590 assessable patients who did not have progressive disease after first-line chemotherapy, the median overall survival was 21.6 months for those who received maintenance and second-line therapies (161 patients), 13.1 months for those receiving maintenance therapy and no second-line therapy (35 patients), 17.7 months for those receiving second-line therapy without maintenance (283 patients), and 11.0 months for those not receiving second-line therapy without maintenance (111 patients), respectively.

disadvantages of maintenance therapy, such as cost, toxicity and loss of drug holidays, further investigation is needed to define the selection criteria of patients who could skip maintenance therapy without compromising the survival benefit conferred by active second-line chemotherapy.

\section{Conflict of Interest}

The Authors declare that they have no conflict of interest in regard to this study.

\section{Acknowledgements}

This study was supported by the Comprehensive Support Project for Oncology Research (CSPOR) of the Public Health Research Foundation, Japan. CSPOR had no role in the design of the study; 
nor in the collection, management, analysis, or interpretation of the data; preparation, review, or approval of the manuscript; and decision to submit the manuscript for publication.

\section{References}

1 Al-Farsi A and Ellis PM: Treatment paradigms for patients with metastatic non-small cell lung cancer, squamous lung cancer: first, second, and third-line. Front Oncol 4: 157, 2014.

2 Schiller JH, Harrington D, Belani CP, Langer C, Sandler A, Krook J, Zhu J, Johnson DH; Eastern Cooperative Oncology Group: Comparison of four chemotherapy regimens for advanced nonsmall-cell lung cancer. N Engl J Med 346: 92-98, 2002.

3 Shepherd FA, Dancey J, Ramlau R, Mattson K, Gralla R, O'Rourke M, Levitan N, Gressot L, Vincent M, Burkes R, Coughlin S, Kim Y and Berille J: Prospective randomized trial of docetaxel versus best supportive care in patients with nonsmall-cell lung cancer previously treated with platinum-based chemotherapy. J Clin Oncol 18: 2095-2103, 2000.

4 Hanna N, Shepherd FA, Fossella FV, Pereira JR, De Marinis F, von Pawel J, Gatzemeier U, Tsao TC, Pless M, Muller T, Lim HL, Desch C, Szondy K, Gervais R, Shaharyar, Manegold C, Paul S, Paoletti P, Einhorn L and Bunn PA Jr.: Randomized phase III trial of pemetrexed versus docetaxel in patients with non-small-cell lung cancer previously treated with chemotherapy. J Clin Oncol 22: 1589-1597, 2004.

5 Shepherd FA, Rodrigues Pereira J, Ciuleanu T, Tan EH, Hirsh V, Thongprasert S, Campos D, Maoleekoonpiroj S, Smylie M, Martins R, van Kooten M, Dediu M, Findlay B, Tu D, Johnston D, Bezjak A, Clark G, Santabárbara P and Seymour L: Erlotinib in previously treated non-small-cell lung cancer. N Engl J Med 353: 123-132, 2005.

6 Bischoff HG, van den Borne B, Pimentel FL, Arellano J, Langer $\mathrm{F}$, Leschinger MI and Thatcher N: Observation of the treatment and outcomes of patients receiving chemotherapy for advanced NSCLC in Europe (ACTION study). Curr Med Res Opin 26: 1461-1470, 2010.

7 Moro-Sibilot D, Vergnenegre A, Smit EF, Toy E, Parente B, Schmitz S, Kraaij K, Visseren-Grul C, Soldatenkova V, Arellano $\mathrm{J}$ and Leteneux C: Second-line therapy for NSCLC in clinical practice: baseline results of the European SELECTION observational study. Curr Med Res Opin 26: 2661-2672, 2010.

8 Gridelli C, Ardizzoni A, Barni S, Crinò L, Caprioli A, Piazza E, Lorusso V, Barbera S, Zilembo N, Gebbia V, Adamo V, Pela R, Marangolo M, Morena R, Filippelli G, Buscarino C, Alabiso O, Maione P, Venturino P, De Marinis F: Medical treatment choices for patients affected by advanced NSCLC in routine clinical practice: results from the Italian observational "SUN" (Survey on the lUng cancer maNagement) study. Lung Cancer 74: 462468, 2011 .

9 Sun JM, Park JO, Won YW, Kim JH, Yun J, Lee J, Park YH, Ahn JS, Ahn MJ and Park K: Who are less likely to receive subsequent chemotherapy beyond first-line therapy for advanced non-small cell lung cancer? Implications for selection of patients for maintenance therapy. J Thorac Oncol 5: 540-545, 2010.

10 Gerber DE, Rasco DW, Le P, Yan J, Dowell JE and Xie Y: Predictors and impact of second-line chemotherapy for advanced non-small cell lung cancer in the United States: real-world considerations for maintenance therapy. J Thorac Oncol 6: 365371,2011 .
11 Gerber DE and Schiller JH: Maintenance chemotherapy for advanced non-small-cell lung cancer: new life for an old idea. $\mathrm{J}$ Clin Oncol 31: 1009-1020, 2013.

12 Ciuleanu T, Brodowicz T, Zielinski C, Kim JH, Krzakowski M, Laack E, Wu YL, Bover I, Begbie S, Tzekova V, Cucevic B, Pereira JR, Yang SH, Madhavan J, Sugarman KP, Peterson P, John WJ, Krejcy K and Belani CP: Maintenance pemetrexed plus best supportive care versus placebo plus best supportive care for non-small-cell lung cancer: a randomised, double-blind, phase 3 study. Lancet 374: 1432-1440, 2009.

13 Cappuzzo F, Ciuleanu T, Stelmakh L, Cicenas S, Szczésna A, Juhász E, Esteban E, Molinier O, Brugger W, Melezínek I, Klingelschmitt G, Klughammer B, Giaccone G; SATURN investigators: Erlotinib as maintenance treatment in advanced non-small-cell lung cancer: a multicentre, randomised, placebocontrolled phase 3 study. Lancet Oncol 11: 521-529, 2010.

14 Fidias PM, Dakhil SR, Lyss AP, Loesch DM, Waterhouse DM, Bromund JL, Chen R, Hristova-Kazmierski M, Treat J, Obasaju CK, Marciniak M, Gill J and Schiller JH: Phase III study of immediate compared with delayed docetaxel after front-line therapy with gemcitabine plus carboplatin in advanced nonsmall-cell lung cancer. J Clin Oncol 27: 591-598, 2009.

15 Perol M, Chouaid C, Perol D, Barlési F, Gervais R, Westeel V, Crequit J, Léna H, Vergnenègre A, Zalcman G, Monnet I, Le Caer H, Fournel P, Falchero L, Poudenx M, Vaylet F, SéguraFerlay C, Devouassoux-Shisheboran M, Taron M and Milleron B: Randomized, phase III study of gemcitabine or erlotinib maintenance therapy versus observation, with predefined second-line treatment, after cisplatin-gemcitabine induction chemotherapy in advanced non-small-cell lung cancer. J Clin Oncol 30: 3516-3524, 2012.

16 Schnipper LE, Davidson NE, Wollins DS, Tyne C, Blayney DW, Blum D, Dicker AP, Ganz PA, Hoverman JR, Langdon R, Lyman GH, Meropol NJ, Mulvey T, Newcomer L, Peppercorn J, Polite B, Raghavan D, Rossi G, Saltz L, Schrag D, Smith TJ, Yu PP, Hudis CA, Schilsky RL, American Society of Clinical Oncology: American Society of Clinical Oncology Statement: A Conceptual framework to assess the value of cancer treatment options. J Clin Oncol 33: 2563-2577, 2015.

17 Detterbeck FC, Boffa DJ and Tanoue LT: The new lung cancer staging system. Chest 136: 260-271, 2009.

18 Paz-Ares L, de Marinis F, Dediu M, Thomas M, Pujol JL, Bidoli P, Molinier O, Sahoo TP, Laack E, Reck M, Corral J, Melemed S, John W, Chouaki N, Zimmermann AH, Visseren-Grul C and Gridelli C: Maintenance therapy with pemetrexed plus best supportive care versus placebo plus best supportive care after induction therapy with pemetrexed plus cisplatin for advanced non-squamous non-small-cell lung cancer (PARAMOUNT): a double-blind, phase 3, randomised controlled trial. Lancet Oncol 13: $247-255,2012$. 